\title{
THE PLASMA LIPIDS IN CORONARY ARTERY DISEASE
}

\author{
BY \\ M. F. OLIVER* AND G. S. BOYD $\dagger$ \\ From the Dept. of Cardiology, Royal Infirmary, Edinburgh, and the Dept. of Biochemistry, University of Edinburgh
}

Received June 8, 1953

In the vast majority of patients coronary artery disease is a manifestation of atherosclerosis. Many diseases that favour the development of atherosclerosis are associated with disturbances in the plasma lipids (Hirsch and Weinhouse, 1943; Gould, 1951), and the high concentration of cholesterol in the arterial plaques has focused attention on the relationship of lipid metabolism to atherosclerosis. The lipid composition of atherosclerotic plaques and of plasma is similar enough to suggest that the lipids of the plaques may have their origin in the plasma (Weinhouse and Hirsch, 1940; Buck and Rossiter, 1951) and labelled cholesterol studies have shown that this plasma lipid is, in fact, incorporated into the atherosclerotic plaque (Biggs et al., 1952). Less comprehensive studies of the plasma lipids in normal subjects compared with patients with coronary artery disease have been made in the United States (Morrison et al., 1948; Gertler et al., 1950; Steiner et al., 1952). It was thought that a larger study, precisely controlled in respect of age and sex, would be of value especially if conducted in Britain where the dietary habits differ to some extent from those elsewhere.

\section{METHOD}

The subjects were 200 consecutive admissions with coronary artery disease and 200 miscellaneous inpatient controls. In the coronary artery disease group, there was electrocardiographic confirmation of myocardial infarction in 170, and of ischæmia before or after the Master two-step test in 30 who presented clinically with angina of effort; any subject who lacked cardiographic confirmation of coronary artery disease was excluded. Adequate controls were very difficult to obtain from a hospital population, but were carefully selected from convalescent in-patients, who had no history or clinical features of atherosclerosis, cardiac, hepatic, metabolic, or renal disease, nor of any other condition known to influence the plasma lipids. The coronary artery disease group was completed first, and the mean age of each decade of both sexes was determined; the control group was then completed so that the mean age, and number of cases in each decade, would correspond with the coronary artery disease group.

In a small pilot study an irregular diurnal variation in plasma cholesterol was observed thus it was decided that all samples should be withdrawn between 8 and 8.30 a.m. in the fasting state. No blood sample taken during anticoagulant therapy has been included in this series. Similarly, no blood sample taken within five weeks of the occurrence of myocardial infarction has been included. All subjects were receiving a light ward or weight-reducing diet.

Plasma free and total cholesterol (hence ester cholesterol by difference) were estimated by the SperrySchoenheimer digitonin method as modified by Sperry and Webb (1950). Plasma lipid phosphorous was estimated by the molybdenum-blue method of Allen (1940). The phospholipid content of plasma has been calculated by multiplying the lipid phosphorus value by 25 . The precise details of the analytical procedures have been reported previously (Oliver and Boyd, 1953). The spectrophotometer was calibrated each day using analytical reagent grade standards. Serial lipid determinations on the same plasma sample agreed to within \pm 2 per cent. Repeated plasma lipid determinations on a group of normal males over many weeks showed less than 7 per cent variation.

\section{RESULTS}

Fig. 1 is a histogram of the age distribution of the 149 men and 51 women who made up the 200 consecutive admissions with coronary artery disease. Its pattern with the maximal incidence in

* Kirk Duncanson Research Fellow of the Royal College of Physicians, Edinburgh.

$\dagger$ Imperial Chemical Industries Research Fellow. 
men in the 50-59 age group, and in women in the 60-69 age group, is familiar. The ratio of men to women decreased from 4 to 1 in the 30-59 groups, to 2 to 1 in the 60-69 group, and 1 to 1 in the over 70 group.

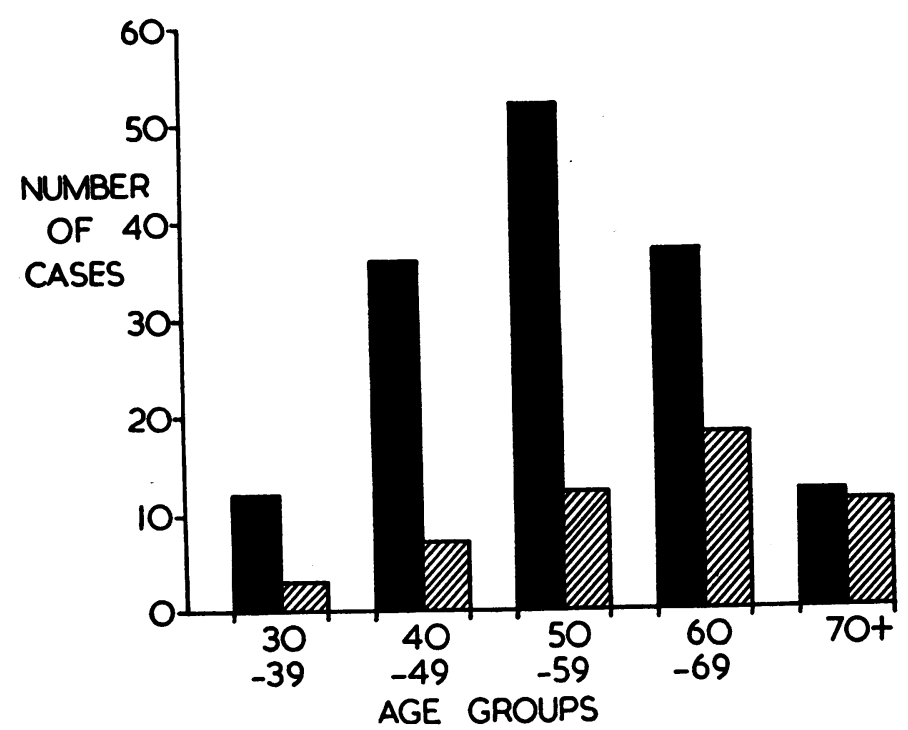

FIG. 1.-A histogram showing the age distribution of the 200 consecutive admissions with coronary artery disease. Black blocks represent men and shaded blocks represent women.

The results of the plasma lipids of each group were contrasted by decades and were expressed separately for the sexes; the standard errors of the means are shown in Fig. 2 to 5 . Fig. 2 represents the mean plasma total cholesterol, and Fig. 4 the mean plasma total-cholesterol:phospholipid ratio, in the men. Table I shows the actual values of these means together with the standard deviations

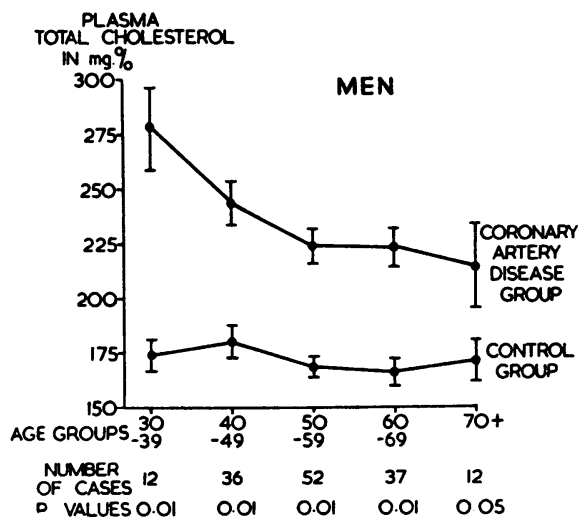

FIG. 2-The mean plasma total cholesterol values for men of the coronary artery disease group and of the control group. The number of cases in each group are indicated. Tests of significance at each decade are shown by the upper limits of the $P$ values.

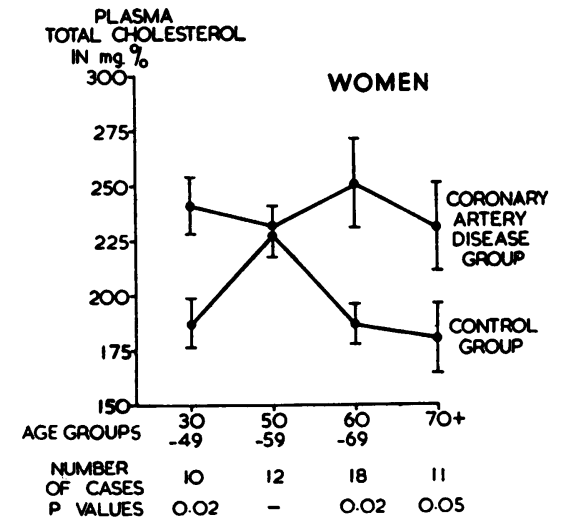

Fig. 3.-The mean plasma total cholesterol values for women of the coronary artery disease group and of the control group (see Fig. 2). 
TABLE I

Plasma Total-Cholesterol and Other Findings in Men

\begin{tabular}{|c|c|c|c|c|c|c|c|c|}
\hline Decades & No. & $\begin{array}{c}\text { Mean } \\
\text { age }\end{array}$ & \begin{tabular}{|c|} 
Plasma total- \\
cholesterol \\
in mg. per \\
$100 \mathrm{ml}$.
\end{tabular} & $\begin{array}{l}\text { Standard } \\
\text { deviation }\end{array}$ & $\begin{array}{l}\text { Range of } \\
\text { plasma total- } \\
\text { cholesterol }\end{array}$ & $\begin{array}{c}\text { Plasma total- } \\
\text { cholesterol: } \\
\text { phospholipid } \\
\text { ratio }\end{array}$ & $\begin{array}{l}\text { Standard } \\
\text { deviation }\end{array}$ & $\begin{array}{c}\text { Range of } \\
\text { cholesterol: } \\
\text { phospholipid } \\
\text { ratio }\end{array}$ \\
\hline & & & \multicolumn{3}{|c|}{ Coronary Artery Disease } & & & \\
\hline $\begin{array}{l}30-39 \\
40-49 \\
50-59 \\
60-69 \\
70+\end{array}$ & $\begin{array}{l}12 \\
36 \\
52 \\
37 \\
12\end{array}$ & $\begin{array}{l}36 \\
45 \\
54 \\
64 \\
75\end{array}$ & $\begin{array}{l}278 \\
243 \\
224 \\
223 \\
214\end{array}$ & $\begin{array}{l} \pm 64 \\
\pm 60 \\
\pm 59 \\
\pm 57 \\
\pm 66\end{array}$ & \begin{tabular}{|}
$201-428$ \\
$132-405$ \\
$120-424$ \\
$117-430$ \\
$134-340$
\end{tabular} & $\begin{array}{l}0.99 \\
0.93 \\
0.90 \\
0.88 \\
0.91\end{array}$ & $\begin{array}{l} \pm 0.12 \\
\pm 0.14 \\
\pm 0.12 \\
\pm 0.14 \\
\pm 0.14\end{array}$ & $\begin{array}{l}0 \cdot 79-1 \cdot 23 \\
0.58-1 \cdot 16 \\
0 \cdot 63-1 \cdot 17 \\
0 \cdot 53-1 \cdot 17 \\
0.66-1.22\end{array}$ \\
\hline \multicolumn{9}{|c|}{ Controls } \\
\hline $\begin{array}{l}30-39 \\
40-49 \\
50-59 \\
60-69 \\
70+\end{array}$ & $\begin{array}{l}12 \\
36 \\
52 \\
37 \\
12\end{array}$ & $\begin{array}{l}36 \\
45 \\
54 \\
64 \\
75\end{array}$ & $\begin{array}{l}174 \\
180 \\
168 \\
166 \\
171\end{array}$ & $\begin{array}{l} \pm 22 \\
\pm 33 \\
\pm 30 \\
\pm 42 \\
\pm 34\end{array}$ & \begin{tabular}{|l|}
$127-206$ \\
$110-234$ \\
$106-230$ \\
$100-265$ \\
$124-242$
\end{tabular} & $\begin{array}{l}0.80 \\
0.84 \\
0 \cdot 82 \\
0 \cdot 80 \\
0 \cdot 77\end{array}$ & $\begin{array}{l} \pm 0 \cdot 15 \\
\pm 0 \cdot 15 \\
\pm 0 \cdot 10 \\
\pm 0 \cdot 14 \\
\pm 0 \cdot 12\end{array}$ & $\begin{array}{l}0.49-0.98 \\
0.52-1.16 \\
0.53-1.07 \\
0.51-1.30 \\
0.54-0.90\end{array}$ \\
\hline
\end{tabular}

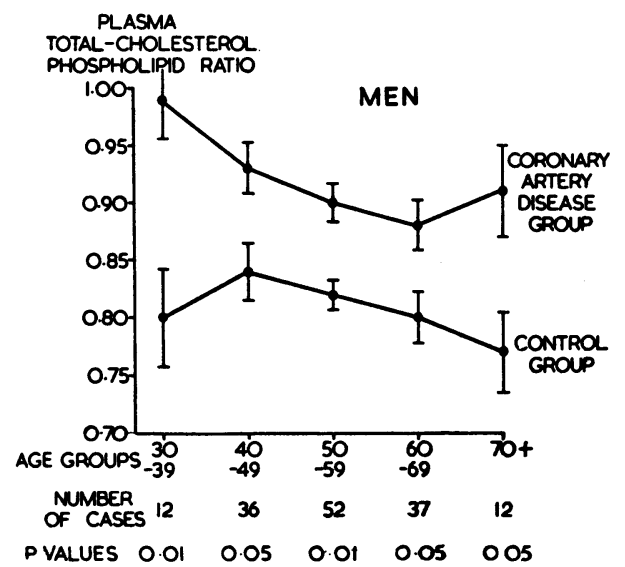

Fig. 4.-The mean plasma total-cholesterol: phospholipid values for men of the coronary artery disease group and of the control group. The number of cases in each group are indicated. Tests of significance at each decade are shown by the upper limits of the $P$ values.

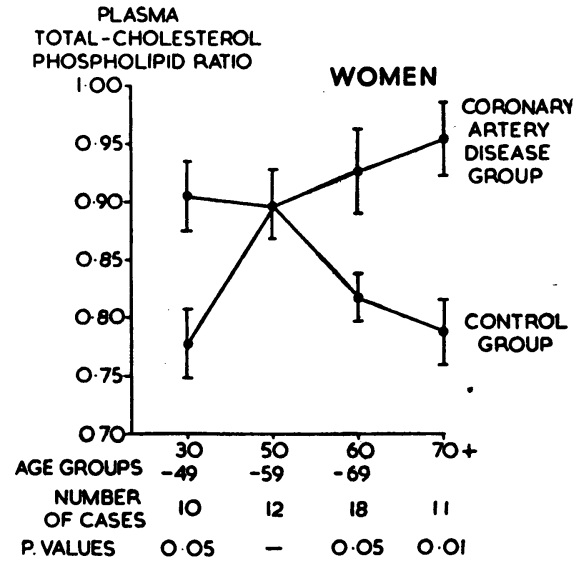

Fig. 5.-The mean plasma total-cholesterol: phospholipid ratio values for women of the coronary artery disease group and of the control group (see Fig. 4).

and ranges. There was significant elevation of plasma total cholesterol and plasma total-cholesterol:phospholipid ratio in all decades in the coronary artery disease group; this significance may, however, only be applied to the group of subjects and not to an individual as there were instances of overlap from one group into the other. Maximal elevation occurred in the earliest decade of the study in men with coronary artery disease. There was no progressive rise with increasing age in the value of plasma total cholesterol in the control group.

Fig. 3 represents the mean plasma total cholesterol, and Fig. 5 the mean plasma total-cholesterol: phospholipid ratio for the women; Table II shows the actual values of these means together with the standard deviations and ranges. As for the men, there was significant overall elevation of these values in all decades, except the sixth, and there was no progressive rise with increasing age in the 
TABLE II

Plasma Total-Cholesterol and Other Findings in Women

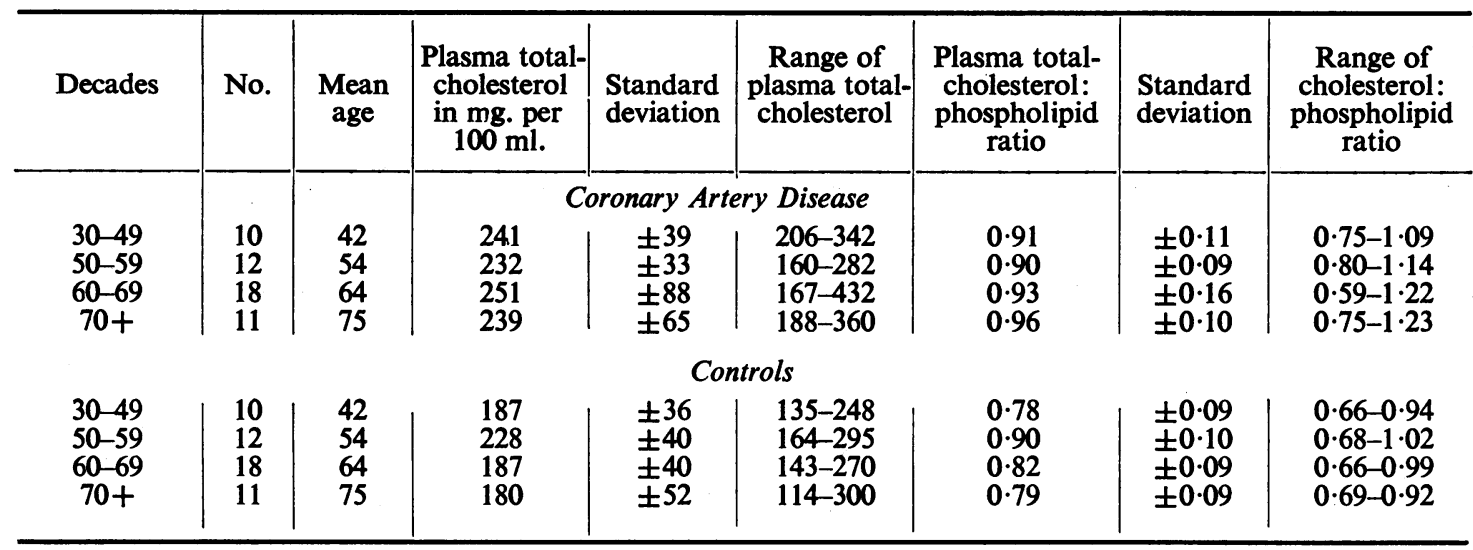

control group. However, in women with coronary artery disease there was no hypercholesterolæmia in the earliest age group of this study. Moreover, in women in the sixth decade the mean plasma lipid results of both the control group and coronary artery disea se group were identical.

It must be emphasized that the means of each decade are derived from separate groups, and thus it cannot be concluded that with advancing years the plasma lipids of an individual will necessarily follow any of these curves.

\section{Discussion}

Provided the subjects of this study are representative of the coronary artery disease population and the normal population, these results show that plasma total cholesterol and the plasma totalcholesterol:phospholipid ratio are both raised in coronary artery disease in Britain; the observations of Gertler ęt al. (1950), Steiner et al. (1952), and other smaller studies conducted in the United States are thus confirmed. An exception to this generalization has occurred in this study in the sixth decade in women and will be discussed later.

While there is no doubt regarding the significance of the elevation of plasma total cholesterol in coronary artery disease, it has been suggested that the ratio of plasma total cholesterol to the plasma phospholipids may be a more important measurement of disturbance of lipid metabolism in atherosclerosis (Ahrens and Kunkel, 1949; Ladd et al., 1949). These authors suggested that the plasma phospholipids may, along with other factors, stabilize the colloidal dispersion of plasma cholesterol. Hence a relative decrease in plasma phospholipids may favour cholesterol deposition. If the phospholipids have a protective action against cholesterol deposition, then, in order to maintain the stability of the colloids, any rise in plasma total cholesterol must be accompanied by a corresponding rise in the plasma phospholipids. In fact there was no corresponding increase in plasma phospholipids in the coronary artery disease group of this study, and thus there was elevation of the plasma total-cholesterol:phospholipid ratio. This confirms the observations made in coronary artery disease by Gertler et al. (1950), Morrison et al. (1950), Steiner et al. (1952) and others.

It is of interest that the most significant rise in plasma total cholesterol and the plasma totalcholesterol:phospholipid ratio in the coronary artery disease group occurred in men under 40. A greater degree of hypercholesterolæmia may be necessary for the premature development of coronary artery disease, and exposure to a high blood cholesterol for a short period may show the same deleterious effect on the coronary arteries that is produced by milder but more longstanding elevation. Duff and McMillan (1951), however, suggested that patients with hypercholesterolæmia and premature coronary artery disease should be grouped with those who suffer from 
hypercholesterolæmia from other causes, and that they are not representative of most atherosclerotic subjects.

There was, in the control group of both sexes, no progressive rise in plasma total cholesterol with increasing age. The results obtained from the fourth decade onwards in this British study differ from the observations, also on normal subjects, in the much larger Minnesota series, which showed an upward trend of serum cholesterol with increasing age (Keys et al., 1950); our results, however, correspond with the smaller series observed in Naples by the same author (Keys et al., 1952). Both the Minnesota and Neapolitan studies and also a small British study of 46 subjects with a mean age of 22 years (Tanner, 1951) showed a rise in serum cholesterol with increasing age during the second and third decades, but it was not until the fourth decade, where our series started, that Keys' two groups diverged; subsequently our study corresponded to the Neapolitan group. Keys suggested that the difference between the Minnesota and Naples groups might be due to the lower fat and lower animal protein intake of the latter.

In women, in all decades except the sixth, the plasma lipid values of the coronary artery disease group differed significantly from the control group. In the sixth decade, however, the mean plasma total cholesterol and the mean plasma total-cholesterol:phospholipid ratio of the two groups were identical. The rise of these values in the control group above the values for adjacent age groups is significant $(\mathrm{P}<0.05)$. There is at present no other comparable study of these lipid values with advancing years in normal women, but, on the assumption that this rise at the sixth decade is real, then their behaviour in a group of supposedly normal subjects is unexpected and requires consideration. Hypertension and obesity are more common after the menopause, but neither would seem to influence these observations; all the control subjects had a diastolic pressure of less than 90 , and a morphological study employing a ponderal index assessment (Sheldon et al., 1940), did not show any tendency to endomorphy in this decade in the controls. The rise in these plasma lipid values occurred in the decade immediately after the menopause, and might be related to the hormonal disturbance of the menopause and, in particular, to œstrogen withdrawal at that time. It has previously been suggested that these plasma lipid values may be influenced by endogenous œstrogen secretion in normal young women (Oliver and Boyd, 1953). Explanation of the significant fall in these plasma lipid values during the subsequent decades of the control group is not readily forthcoming. A variety of conditions commonly occur after the menopause, which, on the basis of our rigid criteria for the selection of controls, exclude subjects from the later decades of the control group; thus the subjects included in later decades are derived from a diminishing "population," which introduces a sampling error. It seems possible that any hormonal imbalance affecting the plasma lipids at or after the menopause may be temporary, and that subsequently, even although sex hormone secretion is minimal, the lipids may in some way regain their former equilibrium. If there is, in fact, a hormonal basis for the rise in these plasma lipid values in the control group, the coronary artery disease group is not similarly influenced, at any rate, in this decade. It is well known that coronary artery disease is uncommon before the menopause, and it is possible that subjects with established atherosclerosis and elevated cholesterol levels are not affected by the hormonal disturbance of the menopause in the same manner as normal women.

\section{CONCLUSIONS}

Plasma free and total cholesterol and plasma phospholipids were estimated in 200 subjects with electrocardiographic proof of coronary artery disease and in 200 controls, who were matched to the pathological group precisely in respect of age and sex.

There was significant elevation of the plasma total cholesterol and of the plasma total-cholesterol: phospholipid ratio in the coronary artery disease group at all ages and in both sexes, with the exception of the sixth decade in women.

Hypercholesterolæmia occurred in the small group of men with coronary artery disease under the age of 40 .

There was no progressive rise in plasma total cholesterol or the plasma total-cholesterol:phospholipid ratio with increasing age in the control group of both sexes. At the sixth decade in 
women the mean plasma total cholesterol and the mean plasma total-cholesterol:phospholipid ratio of the control group rose to the coronary artery disease group level.

Some of the relationships of these plasma lipid patterns to coronary artery disease are discussed.

We wish to thank Dr Rae Gilchrist and Professor G. F. Marrian, F.R.S., of our respective departments for their advice and encouragement, and Miss Anne B. Duthie for skilled technical assistance. This work was supported by a grant from the Advisory Committee on Medical Research (Scotland) as part of a programme of study on coronary atery disease.

\section{REFERENCES}

Ahrens, E. H., and Kunkel, H. G. (1949). J. exp. Med., 90, 409.

Allen, R. J. L. (1940). Biochem, J., 34, 858.

Biggs, M. W., Kritchevsky, D., Colman, D., Gofman, J. W., Jones, H. B., Lindgren, F. T., Hyde, G., and Lyon. T. P. (1952). Circulation, 6, 359.

Buck, R. C., and Rossiter, R. J. (1951). Arch. Path., 51, 224.

Duff, G. L., and McMillan, G. C. (1951). Amer. J. Med., 11, 92.

Gertler, M. M., Garn, S. M., and Lerman, J. (1950). Circulation, 2, 205.

Gould, R. G. (1951). Amer. J. Med., 11, 209.

Hirsch, E. F., and Weinhouse, S. (1943). Physiol. Rev., 23, 185.

Keys, A., Mickelsen, O., Miller, E. v O., Hayes, E. R., and Todd, R. L. (1950). J. clin. Invest., $29,1347$.

Keys, A., Fidanza, F., Scardi, V., and Bergami, G. (1952). Lancet, 2, 209.

Ladd, A. T. Kellner, A., and Correll, J. W. (1949). Fed. Proc., 8, 360.

Morrison, L. M., Hall, L., and Chaney, A. L. (1948). Amer. J. med. Sci., 216, 32.

Morrison, L. M., Gonzalez, P., and Wolfson, E. (1950). Circulation, 2, 472.

Oliver, M. F., and Boyd, G. S. (1953). Clin. Sci., 12, 217.

Sheldon, W. H., Steven, S. S., and Tucker, W. B. (1940). The Varieties of Human Physique. Harper \& Bros., N.Y. and London.

Sperry, W. M., and Webb, M. (1950). J. biol. Chem., 187, 97.

Steiner, A., Kendall, F. E., and Mathers, J. A. L. (1952). Circulation, 5, 605.

Tanner, J. M. (1951). J. Physiol., 115, 371.

Weinhouse, S., and Hirsch, E. F. (1940). Arch. Path., 30, 856. 